\title{
PENGEMBANGAN GAME EDUKASI BERBASIS E-LEARNING PADA MUATAN IPA MATERI EKOSISTEM KELAS V SEKOLAH DASAR
}

\author{
Andi Salsabila ${ }^{1}$ Edwita $^{2}$, A.R. Supriatna ${ }^{3}$ \\ Fakultas Ilmu Pendidikan, Universitas Negeri Jakarta \\ e-mail: andishella8@gmail.com
}

\section{ABSTRAK}

Penelitian ini bertujuan untuk menghasilkan produk berupa game edukasi berbasis $e$-learning yang berisi konten IPA dalam materi ekosistem untuk kelas V Sekolah Dasar. Pengembangan game edukasi berbasis e-learning ini menggunakan metode Research and Development. Model pengembangan yang digunakan adalah model ADDIE dengan rincian sebagai berikut: (1) Analisis; (2) Desain; (3) Pengembangan; (4) Implementasi; dan (5) Evaluasi. Subjek penelitian meliputi dua validator yaitu ahli materi dan ahli media, serta peserta didik kelas $\mathrm{V}$ sekolah dasar yang berjumlah 3 orang untuk evaluasi perorangan dan 6 orang untuk evaluasi kelompok kecil. Hasil penelitian menunjukkan kelayakan game edukasi berbasis e-learning dengan persentase $90 \%$ dari ahli materi dan $80 \%$ dari ahli media dalam kategori "sangat baik". Hasil uji coba peserta didik memperoleh persentase rata-rata $98 \%$ dalam kategori "sangat baik". Sehingga dapat disimpulkan bahwa game edukasi berbasis e-learning sangat cocok digunakan pada muatan IPA materi ekosistem untuk kelas V Sekolah Dasar.

\section{Kata Kunci: Penelitian dan Pengembangan, Game Edukasi, E-learning, IPA}

\section{ABSTRACT}

This study aims to produce a product in the form of educational game-based on e-learning containing science content in ecosystem materials for 5th grade of Elementary School. The development of educational game-based on e-learning uses Research and Development methods. The development model used is the ADDIE model with the following details: (1) Analysis; (2) Design; (3) Development; (4) Implementation; and (5) Evaluation. The research subjects were two validator namely material experts and media experts, as well as fifth grade students totally three people for one to one evaluation and six people for small group evaluation. The results indicated that the feasibility of educational game-based on elearning with a percentage of $90 \%$ from material experts and $80 \%$ from media experts in the "very good" category. The test results from students obtained an average percentage of $98 \%$ in the "very good" category. So it can be concluded that educational game-based on elearning suitable to be used for science content in ecosystem materials for 5th grade of Elementary School.

Keywords: Research and Development, Educational Game, E-learning, Science 


\section{PENDAHULUAN}

Bidang pendidikan cukup mendapatkan dampak yang berarti karena perkembangan teknologi. Hal ini ditandai sebagai era digital learning atau e-learning. Sebuah penelitian mengungkapkan bahwa konsep e-learning mentransformasikan pendidikan konvensional ke digital dalam pembelajaran (Ucu et al., 2018). Elyas mengungkapkan bahwa e-learning adalah pembelajaran yang menggunakan internet sehingga memberikan fleksibelitas dalam mengakses materi kapan saja dan di mana saja (Elyas, 2018). Secara umum terdapat dua persepsi dasar mengenai e-learning yaitu electronic based e-learning yang memanfaatkan teknologi informasi komunikasi berupa elektronik, seperti internet, computer, proyektor, dll. Selain itu, terdapat internet based yang menggunakan fasilitas internet dan bersifat online dalam pembelajaran (Rusli et al., 2020)

Pada konsep e-learning, pendidik harus memanfaatkan kemajuan teknologi dalam proses pembelajaran yang juga harus aktif dan bermakna, khususnya pada muatan Ilmu Pengetahuan Alam di Sekolah Dasar. Prasetyo mengungkapkan bahwa kesempatan yang diberikan untuk mengembangkan kreativitas peserta didik dalam pembelajaran IPA di SD/MI belum maksimal sehingga terjadinya pembelajaran yang kurang bermakna (Prasetyo, 2017). Sebuah penelitian juga mengungkapkan bahwa pada pembelajaran Ilmu Pengetahuan Alam, bukan hanya sebagai objek untuk dipelajari, melainkan juga sebagai media atau sumber belajar bagi peserta didik (Manalu et al., 2019). Pada kurikulum 2013 yang berbasis kompetensi memiliki aspek kognitif, afektif, dan psikomotorik untuk menunjukkan kemajuan pembelajaran peserta didik.(KEMENDIKBUD, 2014). Dalam pembelajaran IPA di Sekolah Dasar, guru harus menciptakan kegiatan yang menambah wawasan tentang IPA dengan melibatkan peserta didik menggunakan media pembelajaran interaktif agar terciptanya pembelajaran yang menyenangkan. Pada e-learning, memerlukan bantuan dari media berbasis teknologi sebagai penyalur informasi yang luas agar dapat dijangkau oleh peserta didik. Selain itu, Arsyad mengungkapkan bahwa media digunakan untuk menyampaikan pesan atau informasi dalam pembelajaran sehingga menumbuhkan minat dan menarik perhatian peserta didik dalam belajar (Arsyad, 2014). Sebuah penelitian juga mengungkapkan bahwa media pembelajaran memiliki fungsi untuk menciptakan suasana belajar yang menyenangkan (Suryani et al., 2018).

Berdasarkan hasil wawancara dengan peserta didik kelas V SDN Menteng 03, didapatkan informasi bahwa peserta didik mengalami kesulitan pada muatan IPA karena terlalu banyak materi yang harus dihafal. Selain itu, peserta didik juga merasakan jenuh dan bosan saat pembelajaran jarak jauh. Oleh karena itu, peserta didik menginginkan pembelajaran yang seru dan menyenangkan. Peneliti juga melakukan wawancara dengan guru kelas V di SDN Menteng 03 dan didapatkan informasi bahwa selain buku, media zoom dan Microsoft PowerPoint juga digunakan oleh guru untuk menjelaskan materi IPA yang belum bisa dipahami peserta didik. Namun, berdasarkan kegiatan observasi saat PKM yang telah dilakukan di SDN Menteng 03, powerpoint masih dibuat sangat sederhana dan belum mampu melibatkan peserta didik secara aktif dalam pembelajaran. Selain itu, guru juga menggunakan buku siswa untuk latihan soal yang diberikan kepada peserta didik.

Penggunaan game edukasi berbasis e-learning diperkirakan akan menciptakan proses pembelajaran IPA lebih menyenangkan. Game adalah kegiatan yang bersifat menyenangkan, membuat gembira, dan dapat membantu perkembangan individu secara keseluruhan (Purnama et al., 2019). Edukasi adalah proses seseorang yang menghasilkan suatu perubahan dari tindakannya melalui belajar (Puspitarini et al., 2016). Game edukasi berbasis e-learning dapat disimpulkan sebagai media pembelajaran berupa game yang dapat diakses menggunakan internet sehingga dapat dilakukan secara fleksibel.

Game edukasi berbasis e-learning dapat dikatakan sebagai media pembelajaran yang praktis. Hal ini dapat dilihat berdasarkan penelitian terdahulu yang dilakukan oleh Ari 
Sumitro dan Muh.Zuhrie yang mengembangkan game edukasi maze runer sebagai media pembelajaran. Peneliti Ari Sumitro dan Muh.Zuhrie beranggapan bahwa dengan menggunakan media pemainan, proses pembelajaran di dalam kelas akan lebih menyenangkan dan membuat peserta didik lebih aktif (Sumitro \& Zuhrie, 2019). Selanjutnya, hasil penelitian terdahulu yang dilakukan oleh peneliti Alfrina Mewengkang dan kawankawan yang mengembangkan game edukasi berbasis mobile. Penelitia Alfrina Mewengkang dan kawan-kawan beranggapan bahwa pada materi ekosistem laut, peserta didik sering kali jenuh karena hanya belajar melalui buku dan memerlukan media game edukasi yang dapat membantu proses pembelajaran dengan menarik dan membuat peserta didik dapat belajar dengan cepat dan menyenangkan (Mewengkang et al., 2018).

Berdasarkan permasalahan tersebut, peneliti tertarik untuk melakukan penelitian pengembangan game edukasi dengan judul "Pengembangan Game Edukasi Berbasis ELearning pada Muatan IPA Materi Ekosistem Kelas V Sekolah Dasar." Game edukasi dikembangkan menggunakan scratch. Scratch adalah sebuah aplikasi untuk membuat media pembelajaran dengan mudah terkait bahasa pemrograman (Sudihartinih et al., 2021). Game edukasi berbasis e-learning dikembangkan berupa labirin yang terdiri dari level 1-10 dan dapat diakses melalui website. Melalui game edukasi berbasis e-learning ini, diharapkan peserta didik dapat lebih tertarik untuk belajar mandiri sambil bermain dalam proses pembelajaran.

\section{METODE}

Penelitian dan pengembangan ini bertujuan untuk menghasilkan game edukasi berbasis e-learning muatan IPA materi ekosistem kelas V Sekolah Dasar. Game edukasi berbasis $e$ learning ini diharapkan dapat menjadi media pembelajaran yang menarik, menyenangkan, dapat meningkatkan motivasi dan melatih konsentrasi peserta didik. Pada penelitian ini, peneliti akan menggunakan metode penelitian dan pengembangan atau Research and Development. Metode $R \& D$ adalah metode penelitian yang menghasilkan suatu produk tertentu dan produk tersebut akan diuji kefektifannya (Sugiyono, 2018).

Model pengembangan yang digunakan dalam pengembangan media game edukasi ini adalah $A D D I E$. Model $A D D I E$ merupakan salah satu model desain pembelajaran sistematik. Model ini terdiri atas lima langkah, yaitu: (1) analisis (analyze), (2) perancangan (design), (3) pengembangan (development), (4) implementasi (implementation), dan (5) evaluasi (evaluation) (Tegeh \& Kirna, 2013) .

Penelitian ini dilakukan di SDN Menteng 03 Jakarta Pusat. Teknik pengumpulan data yang digunakan peneliti adalah wawancara seorang guru kelas $\mathrm{V}$ dan salah satu peserta didik, serta melakukan observasi pembelajaran IPA kelas V Sekolah Dasar yang berjumlah 32 orang untuk menganalisis permasalahan yang ada. Setelah menganalisis, peneliti melakukan perancangan media dan mendesain sesuai yang telah diteliti dan menentukan lingkungan pembelajaran. Peneliti harus memilih tempat dan responden yang akan diujicobakan, dan expert review. (Rayanto \& Sugianto, 2020). Selanjutnya pada tahap pengembangan, peneliti menghasilkan produk yang telah didesain sebelumnya menjadi bentuk fisik. Pembuatan media ini disesuaikan dengan karakteristik peserta didik kelas V sekolah dasar, draft materi berdasarkan kompetensi kurikulum 2013, mendesain buku petunjuk penggunaan, pemilihan warna dan gambar, serta ukuran dan font sesuai dengan peserta didik kelas V sekolah dasar. Produk yang telah dihasilkan harus diukur kevalidan dan keberhasilannya melalui beberapa tahapan yaitu uji ahli dengan melibatkan dosen ahli materi dan dosen ahli media menggunakan instrument penilaian. Setelah itu, peneliti merevisi produk sesuai dengan saran dari para ahli. Selain itu, peneliti juga melakukan uji coba pengguna one to one evaluation 
yang melibatkan 3 orang dan small group evaluation yang melibatkan 6 orang peserta didik kelas V sekolah dasar.

Dalam penelitian pengembangan ini menggunakan teknik analisis data statistik deskriptif kuantitatif. Nasution mengungkapkan bahwa statistika deskriptif menyajikan pengumpulan data bagian statistik tentang suatu hal dalam bentuk yang lebih mudah dipahami (Nasution, 2017). Jenis pengumpulan data menggunakan kuisioner (angket) dengan rating scale data yang diperoleh langsung berupa angka (kuantitatif) (Muchson, 2017). Data yang diperoleh dari validasi ahli selanjutnya dilakukan perhitungan untuk mengetahui kualitas game edukasi berbasis e-learning muatan IPA. Kriteria perhitungan hasil uji coba pada tahap uji validasi ahli dan uji coba peserta didik, yaitu :

$$
\frac{\text { Jumlah skor hasil pengumpulan data }}{\text { Jumlah butir soal X skala poin tertinggi soal }} \text { X } 100
$$

Data kuantitatif ditafsirkan menjadi data kualitatif berdasarkan skor kriteria yang diperoleh dengan acuan yang digunakan yaitu : (Riduwan \& Sunarto, 2013)

Tabel 1. Tabel Penilaian Skor Kriteria

\begin{tabular}{|c|l|c|}
\hline No & \multicolumn{1}{|c|}{ Deskripsi } & Skor \\
\hline 1 & Sangat kurang baik & $0 \%-25 \%$ \\
\hline 2 & Kurang baik & $26 \%-50 \%$ \\
\hline 3 & Baik & $51 \%-75 \%$ \\
\hline 4 & Sangat Baik & $76 \%-100 \%$ \\
\hline
\end{tabular}

\section{HASIL DAN PEMBAHASAN}

Hasil dari tahap analisis berdasarkan observasi dan wawancara oleh guru kelas dan peserta didik kelas $\mathrm{V}$ sekolah dasar diperoleh bahwa dibutuhkan bantuan media pendukung yang dapat meningkatkan daya tarik dan motivasi peserta didik, serta membuat pembelajaran IPA lebih menyenangkan. Oleh karena itu, perlu adanya media pembelajaran berupa game edukasi berbasis e-learning. Hal ini dapat dilihat berdasarkan penelitian terdahulu yaitu peneliti Muh.Zuhrie mengembangkan game edukasi maze runner yang membuat pembelajaran lebih aktif dan menarik. Penelitian yang dilakukan oleh Ari Sumitro dan Muh. Syariffuddien Zuhrie memiliki relevansi dengan penelitian yang dilakukan peneliti yaitu mengembangkan game edukasi berbentuk maze runner. Namun, inovasi yang peneliti kembangkan yaitu pada cara bermain yaitu tidak boleh menyentuh rintangan pada game labirin yang bertujuan untuk melatih konsentrasi peserta didik. Kemudian, peneliti merancang game edukasi berbasis e-learning dengan memerhatikan kriteria game edukasi yang baik. Menurut Hurd dan Jenuings dalam Novaliendry kriteria game edukasi yang baik yaitu; 1) Nilai keseluruhan; 2) Usability; 3) Kesesuaian; 4) Keakuratan; 5) Relevan; 6) Objektifitas; 7) Feedback (Dony Novaliendry, 2013). Game edukasi berbasis e-learning lalu dikembanhkan dengan mendesain layout di storyboard, menyusun draft materi, dan game dikembangkan melalui aplikasi scratch akan diconvert dan dibagikan berupa link website. Setelah itu, pengembangan ini akan divalidasikan oleh validator yaitu ahli materi dan ahli media untuk mendapatkan nilai dan saran dalam memperbaiki produk 
melalui instrument terbuka. Berikut ini hasil dari expert review:

Tabel 2. Hasil validasi ahli media

\begin{tabular}{|c|c|c|c|c|c|}
\hline No & Aspek & $\begin{array}{c}\text { Jumlah } \\
\text { Ahli }\end{array}$ & $\begin{array}{c}\text { Skor } \\
\text { Maksimum }\end{array}$ & $\begin{array}{c}\text { Skor } \\
\text { Perolehan }\end{array}$ & $\begin{array}{c}\text { Skor } \\
\text { Persentase }\end{array}$ \\
\hline 1 & $\begin{array}{l}\text { Tampilan dan } \\
\text { Desain }\end{array}$ & \multirow{4}{*}{1} & 8 & 7 & $87,5 \%$ \\
\hline 2 & $\begin{array}{l}\text { Pengoperasian } \\
\text { Game }\end{array}$ & & 8 & 6 & $75 \%$ \\
\hline 3 & Ketepatan & & 16 & 12 & $75 \%$ \\
\hline 4 & $\begin{array}{l}\text { Penyajian } \\
\text { game }\end{array}$ & & 8 & 7 & $87,5 \%$ \\
\hline \multicolumn{3}{|c|}{ Rata-rata } & 40 & 32 & $80 \%$ \\
\hline
\end{tabular}

Berdasarkan tabel di atas, hasil rekapitulasi penilaian ahli media terhadap game edukasi berbasis e-learning muatan IPA Materi Ekosistem Kelas V SD menunjukkan persentase ratarata kelayakan produk sebesar 80 \% dan termasuk kategori Sangat Baik (SB).

Tabel 3. Hasil validasi ahli materi

\begin{tabular}{|c|c|c|c|c|c|}
\hline No & Aspek & $\begin{array}{l}\text { Jumlah } \\
\text { Ahli }\end{array}$ & $\begin{array}{l}\text { Skor } \\
\text { Maksimum }\end{array}$ & $\begin{array}{l}\text { Skor } \\
\text { Perolehan }\end{array}$ & $\begin{array}{l}\text { Skor } \\
\text { Persentase }\end{array}$ \\
\hline 1 & $\begin{array}{l}\text { Kesesuaian } \\
\text { Materi }\end{array}$ & \multirow{3}{*}{1} & 20 & 17 & $85 \%$ \\
\hline 2 & Objektifitas & & 8 & 8 & $100 \%$ \\
\hline 3 & $\begin{array}{l}\text { Umpan Balik } \\
\text { (feedback) }\end{array}$ & & 12 & 11 & $91,6 \%$ \\
\hline \multicolumn{3}{|c|}{ Rata-rata } & 40 & 36 & $90 \%$ \\
\hline
\end{tabular}

Berdasarkan tabel di atas, hasil rekapitulasi penilaian ahli materi terhadap game edukasi berbasis $e$-learning muatan IPA Materi Ekosistem Kelas V SD menunjukkan persentase ratarata kelayakan produk sebesar $90 \%$ dan termasuk kategori Sangat Baik (SB).

Berdasarkan hasil penilaian uji coba ahli terhadap Pengembangan Game Edukasi Berbasis E-learning Muatan IPA Materi Ekosistem Kelas V SD secara keseluruhan adalah sebagai berikut. 
Tabel 4. Hasil Rekapitulasi Uji Coba Ahli

\begin{tabular}{|l|l|l|l|l|}
\hline No & Nama & Responden & Persentase & Ket. \\
\hline 1 & $\begin{array}{l}\text { Bhakti Prima Findiga } \\
\text { Hermuttaqien, S.Pd., M.Pd }\end{array}$ & Ahli Media & $80 \%$ & SB \\
\hline 2 & Tatang Suratno, M.Pd & Ahli Materi & $90 \%$ & SB \\
\hline \multicolumn{2}{l|}{ Rata-rata } & $\mathbf{8 5 \%}$ & SB \\
\hline
\end{tabular}

Hasil penilaian uji coba ahli yang dilakukan pada Game Edukasi Berbasis E-learning Muatan IPA Materi Ekosistem Kelas V SD menunjukan persentase rata-rata kelayakan produk sebesar $85 \%$ dan termasuk kategori Sangat Baik (SB). Para ahli memberikan saran kepada peneliti sebagai acuan untuk perbaikan media agar menjadi lebih baik lagi dan layak digunakan untuk peserta didik.

Setelah pengembangan game edukasi berbasis e-learning dinyatakan layak oleh dua ahli, kemudian peneliti melakukan uji coba one to one evaluation yang melibatkan 3 orang peserta didik dan small group evaluation yang melibatkan 6 orang peserta didik kelas V sekolah dasar. Berikut hasil uji coba pengguna peserta didik:

Tabel 5. Hasil Uji Coba One to One Evaluation

\begin{tabular}{|c|c|c|c|c|c|}
\hline No & Aspek Penilaian & $\begin{array}{c}\text { Nomor } \\
\text { Kuesioner }\end{array}$ & $\begin{array}{c}\text { Skor } \\
\text { Kriteria }\end{array}$ & $\begin{array}{c}\text { Skor yang } \\
\text { Didapat }\end{array}$ & Persentase \\
\hline \multirow[t]{4}{*}{1} & \multirow{4}{*}{$\begin{array}{l}\text { Tampilan dan } \\
\text { Desain }\end{array}$} & 1 & 3 & 3 & \multirow{16}{*}{$98 \%$} \\
\hline & & 2 & 3 & 3 & \\
\hline & & 3 & 3 & 3 & \\
\hline & & 4 & 3 & 2 & \\
\hline \multirow[b]{2}{*}{2} & \multirow{2}{*}{$\begin{array}{l}\text { Pengoperasian } \\
\text { game }\end{array}$} & 5 & 3 & 3 & \\
\hline & & 6 & 3 & 3 & \\
\hline \multirow[t]{4}{*}{3} & \multirow[t]{4}{*}{ Tipografi } & 7 & 3 & 3 & \\
\hline & & 8 & 3 & 3 & \\
\hline & & 9 & 3 & 3 & \\
\hline & & 10 & 3 & 3 & \\
\hline \multirow[t]{6}{*}{4} & \multirow[t]{5}{*}{ Isi Materi } & 11 & 3 & 3 & \\
\hline & & 12 & 3 & 3 & \\
\hline & & 13 & 3 & 3 & \\
\hline & & 14 & 3 & 3 & \\
\hline & & 15 & 3 & 3 & \\
\hline & Jumlah & 15 & 45 & 44 & \\
\hline
\end{tabular}

Berdasarkan tabel hasil rekapitulasi One to One Evaluation, dapat diketahui bahwa terdapat 4 aspek yang dinilai yaitu tampilan dan desain, pengoperasian game, tipografi, dan isi materi terhadap game edukasi. Media pembelajaran berupa game edukasi berbasis $e$ learning memperoleh skor total 44 dengan kelayakan sebesar 98\%. Berdasarkan kategori kelayakan produk, maka game edukasi berbasis e-learning termasuk dalam kategori sangat baik. 
Tabel 6. Hasil Uji Coba Small Group Evaluation

\begin{tabular}{|c|c|c|c|c|c|}
\hline No & Aspek Penilaian & $\begin{array}{c}\text { Nomor } \\
\text { Kuesioner }\end{array}$ & $\begin{array}{c}\text { Skor } \\
\text { Kriteria }\end{array}$ & $\begin{array}{c}\text { Skor yang } \\
\text { Didapat }\end{array}$ & Persentase \\
\hline \multirow[t]{4}{*}{1} & \multirow{4}{*}{$\begin{array}{l}\text { Tampilan dan } \\
\text { Desain }\end{array}$} & 1 & 6 & 6 & \multirow{16}{*}{$98 \%$} \\
\hline & & 2 & 6 & 6 & \\
\hline & & 3 & 6 & 6 & \\
\hline & & 4 & 6 & 5 & \\
\hline \multirow{2}{*}{2} & \multirow{2}{*}{$\begin{array}{c}\text { Pengoperasian } \\
\text { game }\end{array}$} & 5 & 6 & 5 & \\
\hline & & 6 & 6 & 6 & \\
\hline \multirow[t]{4}{*}{3} & \multirow[t]{4}{*}{ Tipografi } & 7 & 6 & 6 & \\
\hline & & 8 & 6 & 6 & \\
\hline & & 9 & 6 & 6 & \\
\hline & & 10 & 6 & 6 & \\
\hline \multirow[t]{6}{*}{4} & \multirow[t]{5}{*}{ Isi Materi } & 11 & 6 & 6 & \\
\hline & & 12 & 6 & 6 & \\
\hline & & 13 & 6 & 6 & \\
\hline & & 14 & 6 & 6 & \\
\hline & & 15 & 6 & 6 & \\
\hline & Jumlah & 15 & 90 & 88 & \\
\hline
\end{tabular}

Berdasarkan tabel hasil rekapitulasi Small Group Evaluation, dapat diketahui bahwa terdapat 4 aspek yang dinilai yaitu tampilan dan desain, pengoperasian game, tipografi, dan isi materi terhadap game edukasi. Media pembelajaran berupa game edukasi berbasis $e$ learning memperoleh skor total 88 dengan kelayakan sebesar 98\%. Berdasarkan kategori kelayakan produk, maka game edukasi berbasis $e$-learning termasuk dalam kategori sangat baik.

Tabel 7. Hasil Rekapitulasi Uji Coba Produk

\begin{tabular}{|c|c|c|}
\hline No & Uji Coba Produk & Persentase \\
\hline 1 & One to One Evaluation & $98 \%$ \\
\hline 2 & Small Group Evaluation & $98 \%$ \\
\hline \multicolumn{2}{|c|}{ Rata-rata keseluruhan } & $\mathbf{9 8 \%}$ \\
\hline
\end{tabular}

Berdasarkan tabel hasil rekapitulasi uji produk, dapat diketahui bahwa game edukasi berbasis e-learning memperoleh persentase kelayakan sebesar 98\%. Berdasarkan kategori kelayakan produk, maka game edukasi berbasis $e$-learning termasuk dalam kategori sangat baik.

\section{PENUTUP}

Kesimpulan dari penelitian pengembangan ini yaitu produk game edukasi berbasis $e$ learning dapat dikatakan layak diujicobakan sebagai media pembelajaran alternatif berdasarkan kualitas materi, media, dan peserta didik. Berdasarkan penilaian para ahli, produk yang dikembangkan memperoleh persentase sebesar $90 \%$ dari ahli materi dan $80 \%$ dari ahli media. Game edukasi berbasis e-learning juga dapat menarik minat belajar dan peserta didik. Hal ini dapat dilihat berdasarkan pemerolehan hasil rata-rata persentase 
penilaian uji coba produk terhadap peserta didik adalah 98\%. Berdasarkan dalam kategori penilaian, maka produk yang dikembangkan berada pada kategori sangat baik.

\section{UCAPAN TERIMA KASIH}

Peneliti mengucapkan terima kasih kepada Kepala Sekolah dan Guru kelas V yang telah mengizinkan peneliti melakukan penelitian pengembangan di SDN Menteng 03 Jakarta Pusat. Terima kasih kepada peserta didik kelas V SDN Menten 03 yang telah bersedia menjadi uji pengguna pengembangan game edukasi berbasis e-learning ini. Selain itu, terima kasih kepada para dosen ahli yang telah bersedia meluangkan waktunya untuk melakukan validasi terhadap kelayakan produk pengembangan.

\section{DAFTAR PUSTAKA}

Arsyad, A. (2014). Media Pembelajaran. Jakarta: Raja Grafindo Persada.

Dony Novaliendry. (2013). APLIKASI GAME GEOGRAFI BERBASIS MULTIMEDIA INTERAKTIF (STUDI KASUS SISWA KELAS IX SMPN 1 RAO). Jurnal Teknologi Informasi \& Pendidikan, 6(2).

Elyas, A. H. (2018). Penggunaan model pembelajaran e-learning dalam meningkatkan kualitas pembelajaran. Jurnal Warta, 56(04), 1-11. http://jurnal.dharmawangsa.ac.id/index.php/juwarta/article/view/4

KEMENDIKBUD. (2014). Konsep dan Implementasi Kurikulum 2013.

Manalu, L. Y., Sutrisno, \& Hasanah, U. (2019). Hubungan gaya belajar dengan hasil belajar ilmu pengetahuan alam siswa kelas v sekolah dasar. Jurnal PGSD FIP UNJ, 1(1), 1-13. https://doi.org/doi.org/10.21009/DSD.XXX.

Mewengkang, A., Manado, U. N., Tangkawarow, I. R. H., Manado, U. N., Kasehung, H., Manado, U. N., \& Material, O. C. (2018). Pengembangan Game Edukasi Pengenalan Ekosistem Berbasis Mobile. Frontiers: Jurnal Sains Dan Teknologi, 1(April), 27-38. https://doi.org/10.36412/frontiers/001035e1/april201801.03

Muchson. (2017). Statistik Deskriptif (Guepedia (ed.); p. 127). Guepedia.

Nasution, L. M. (2017). STATISTIK DESKRIPTIF Leni Masnidar Nasution. Jurnal Hikmah, $14(1), 49-55$.

Prasetyo, S. (2017). Pengembangan Media Pembelajaran Ipa Berbasis Android Untuk Siswa Sd/Mi. JMIE (Journal of Madrasah Ibtidaiyah Education), 1(1), 122-141. https://doi.org/10.32934/jmie.v1i1.29

Purnama, S., Hijriani, Y. S., \& Heldanita. (2019). Alat Permainan Edukatif Anak Usia Dini (Nita (ed.); 1st ed.). PT Remaja Rosdakarya.

Puspitarini, E. W., Putra, D. W., \& Nugroho, A. P. (2016). Game Edukasi Berbasis Android Sebagai Media Pembelajaran Untuk Anak Usia Dini. J I M P - Jurnal Informatika Merdeka Pasuruan, 1(1), 46-58. https://doi.org/10.37438/jimp.v1i1.7

Rayanto, Y. H., \& Sugianto. (2020). PENELITIAN DAN PENGEMBANGAN MODEL ADDIE R2D2: TEORI DAN PRAKTEK (T. Rokhmawan (ed.)). Lembaga Academic \& Research Institute.

Riduwan, \& Sunarto. (2013). Pengantar Statistika untuk Penelitian Pendidikan, Sosial, Komunikasi, Ekonomi, dan Bisnis. Alfabeta.

Rusli, M., Hermawan, D., \& Supuwiningsi, N. N. (2020). Memahami E-learning: Konsep, Teknologi, dan Arah Perkembangan. Andi (Anggota Ikapi).

Sudihartinih, E., Novita, G., \& Rachmatin, D. (2021). Desain Media Pembelajaran Matematika Topik Luas Daerah Segitiga Menggunakan Aplikasi Scratch. Jurnal Cendekia: Jurnal Pendidikan Matematika, 05(02), 1390-1398.

Sugiyono. (2018). Metode Penelitian Kuantitatif, Kualitatif, dan $R \& D$ (26th ed.). Alfabeta. 
Sumitro, A., \& Zuhrie, M. S. (2019). PENGEMBANGAN GAME EDUKASI MAZE RUNNER SEBAGAI MEDIA PEMBELAJARAN DASAR LISTRIK ELEKTRONIKA SISWA KELAS X DI SMK NEGERI 1 JETIS MOJOKERTO Abstrak. Jurnal Pendidikan Teknik Elektro, 08(2), 241-246.

Suryani, N., Setiawan, A., \& Putria, A. (2018). Media Pembelajaran Inovatif dan Pengembangannya. PT Remaja Rosdakarya.

Tegeh, I. M., \& Kirna, I. M. (2013). Pengembangan Bahan Ajar Metode Penelitian Pendidikan Dengan Addie Model. Jurnal Ika, 11(1), 12-26.

Ucu, N. L., Paturusi, S. D. E., \& Sompie, S. R. U. A. (2018). Analisa Pemanfaatan ELearning Untuk Proses Pembelajaran. Jurnal Teknik Informatika, 13(1). https://doi.org/10.35793/jti.13.1.2018.20196 